\title{
RESEARCH
}

Open Access

\section{Imbalance in glycemic control between the treatment and placebo groups in cardiovascular outcome trials in type 2 diabetes}

\author{
Rumiko Shimazawa ${ }^{1}$ and Masayuki $l k e d a^{2^{*}}$ (D)
}

\begin{abstract}
Background: Glycated hemoglobin (HbA1c) is accepted as the most reliable marker for assessing chronic glycemia. The present study aimed to investigate glycemic control in cardiovascular outcome trials (CVOTs) performed by pharmaceutical sponsors, at the request of the United States Food and Drug Administration (FDA) to ensure that newer hypoglycemic agents do not increase cardiovascular risk for patients with type 2 diabetes.

Methods: We chose ClinicalTrials.gov as a data source to identify randomized, double-blind, placebo-controlled noninferiority trials of newer hypoglycemic agents for which the FDA 2008 guidance required a CVOT involving patients with type 2 diabetes.

Results: We identified 12 CVOTs, all of which were performed in accordance with the FDA guidance and published as of December 2018. Participants received either active treatment or placebo in addition to their existing therapy. On the assumption that HbA1c concentrations would be higher in the placebo group than in the treatment group, the use of open-label glucose lowering agents was encouraged as required to help all patients reach appropriate HbA1c targets according to local guidelines. As a result, the number of patients who received additional hypoglycemic agents during the trial was greater in the placebo group than in the treatment group in 10 of the CVOTs. Although the CVOTs were designed to avoid any imbalance in glycemic control between the groups, HbA1c concentrations were substantially higher in the placebo group than in the treatment group in all CVOTs throughout the observational period. The inferior glycemic control in the placebo groups was not considered in analyzing the outcomes in any of the CVOTs.

Conclusions: The safety and efficacy of new hypoglycemic agents are potentially inflated because the participants in the placebo groups unexpectedly exhibited inferior glycemic control throughout the trial compared with the outcomes in the treatment groups. This imbalance may distort data interpretation and mask potential risks of the drugs. Re-analysis with adjustment for HbA1c concentrations would determine whether the results of these CVOTs were biased by the difference in glycemic control between the treatment and placebo groups and reveal potential effects of the test drugs independent of glycemic control.
\end{abstract}

Keywords: Bias, Cardiovascular diseases, Clinical trials, Drug approval, Glycated hemoglobin, Hypoglycemic agents, Type 2 diabetes mellitus

\footnotetext{
*Correspondence: massie.ikeda@gmail.com

2Department of Medical Informatics, Kagawa University Hospital, Miki-cho,

Kagawa 761-0793, Japan

Full list of author information is available at the end of the article
}

(C) The Author(s). 2019 Open Access This article is distributed under the terms of the Creative Commons Attribution 4.0 International License (http://creativecommons.org/licenses/by/4.0/), which permits unrestricted use, distribution, and reproduction in any medium, provided you give appropriate credit to the original author(s) and the source, provide a link to the Creative Commons license, and indicate if changes were made. The Creative Commons Public Domain Dedication waiver (http://creativecommons.org/publicdomain/zero/1.0/) applies to the data made available in this article, unless otherwise stated. 


\section{Background}

Diabetes treatment is adjusted on the basis of the concentrations of glycated hemoglobin (HbA1c), which is accepted as the most reliable marker to assess chromic glycemia [1]. Regulatory authorities have approved hypoglycemic agents using HbA1c concentrations as the outcome because good glycemic control (defined by specific HbA1c targets) is expected to reduce cardiovascular (CV) risk in patients with type 2 diabetes mellitus (T2D) [2, 3].

This glucocentric approach, however, has been challenged because of controversy over the CV risk associated with specific hypoglycemic agents, notably the peroxisome proliferator-activated receptor agonists, muraglitazar and rosiglitazone [4]. Compared with placebo or pioglitazone, muraglitazar was associated with a greater than 2-fold (relative risk $=2.62,95 \%$ confidence interval $[\mathrm{CI}]=1.36-$ 5.05; $P=0.004$ ) higher incidence of CV events, including all-cause mortality, myocardial infarction, heart failure, and stroke [5]. This report prompted Bristol-Meyers Squibb to withdraw its new drug application for muraglitazar even though the drug had received a recommendation for approval from a United States Food and Drug Administration (FDA) advisory panel [6]. A meta-analysis of rosiglitazone [7] illustrated that the drug was associated with a significant increase in the risk of myocardial infarction (odds ratio $=1.43,95 \% \mathrm{CI}=1.03-1.98 ; P=0.03$ ). In a trial evaluating $\mathrm{CV}$ outcomes in rosiglitazone-treated patients with T2D [8], hospital admission for heart failure or death was more frequent in the rosiglitazone group than in the active control group (hazard ratio $[\mathrm{HR}]=2.10$, 95\% CI $=1.35-3.27 ; P=0.001)$.

These data prompted the FDA to ask sponsors to perform trials as a post-marketing requirement to ensure that new hypoglycemic agents do not increase CV risk to an unacceptable extent. Since the FDA published the trial guidance in December 2008 [9], the number of CV outcome trials (CVOTs) in T2D $[10,11]$ has greatly increased [12]. The FDA guidance states that reliance on HbA1c concentrations remain an acceptable primary efficacy endpoint for approving drugs for the treatment of hyperglycemia secondary to diabetes.

Although the CVOTs were designed to achieve comparable glycemic control between the trial arms, the patients in the placebo group were reported to have higher HbA1c concentrations than those in the test drug group in some of the trials $[10,13]$. This difference in glycemic control has the potential to distort data interpretation and mask the risks of the tested hypoglycemic agents. However, this issue has never been studied in detail; instead, it has been dismissed as negligible on the assumption that HbA1c is not the right outcome for studies of diabetes [14, 15], even though this assumption remains to be validated. Taking these concerns about HbA1c into account, we investigated the differences in glycemic control in the CVOTs performed according the FDA 2008 guidance [9] and evaluated the effects of these differences on the safety and efficacy of the tested hypoglycemic agents.

\section{Methods}

To determine the target CVOTs, we identified newer FDA-approved hypoglycemic agents [16], i.e., dipeptidyl peptidase-4 (DPP-4) inhibitors, glucagon-like peptide 1 (GLP-1) agonists, and sodium glucose cotransporter 2 (SGLT2) inhibitors, indicated for T2D, focusing on studies for which CVOTs were required by the agency [4]. Then, we retrieved CVOTs for these newer hypoglycemic agents designed according to the FDA 2008 guidance [9] and from ClinicalTrials.gov [17], which was a sufficient source for such studies because any trial compliant to the guidance [9] was subject to registration on ClinicalTrials.gov [18]. The selection criteria for CVOTs other than compliance with FDA guidance [9] were as follows: randomized, double-blind, placebo-controlled trial including patients with T2D, and the primary endpoint was "Major Cardiac Adverse Events (MACE)."

\section{Results}

Participant characteristics and trial design (Table 1)

We identified 12 CVOTs [19-32], all of which were performed in accordance with the FDA guidance [9] and published as of December 31, 2018. The test drugs were DPP-4 inhibitors $(n=4)$ [19-23], GLP-1 agonists $(n=5)$ [24-28], and SGLT2 inhibitors $(n=3)$ [29-32]. All of the CVOTs were sponsored by the pharmaceutical companies that had developed the test drugs. Participants had advanced atherosclerotic CV risk or established CV diseases. The patients had a long duration of T2D (mean, 7.1-15.0 years). The baseline mean $\mathrm{HbA1c}$ concentrations ranged from 7.2 to $8.7 \%$. The participants received either active treatment or placebo in addition to their existing therapy. In other words, the comparator arm was not a true placebo because additional glucose-lowering therapies were allowed, even though each of the trials was described as being placebo-controlled. These CVOTs were primarily designed to rule out unacceptable $\mathrm{CV}$ risk, but some were powered to reveal superiority after non-inferiority was demonstrated. The primary outcome was four-component MACE (CV death, nonfatal myocardial infarction, nonfatal stroke, and hospitalization for unstable angina) in two trials [23, 27], whereas, the primary endpoint was three-component MACE (CV death, nonfatal myocardial infarction, and nonfatal stroke) in the other 10 trials.

\section{Glucose control and adverse events in the CVOTs (Table 2)}

On the assumption that HbA1c concentrations would be higher in the placebo group than in the treatment group, 
Table 1 Baseline characteristics of the trial participants and design features of the cardiovascular outcome trials

\begin{tabular}{|c|c|c|c|c|c|c|c|c|c|c|}
\hline Trial & $\begin{array}{l}\text { Drug } \\
\text { (Class) }\end{array}$ & $\begin{array}{l}\text { Year started/ } \\
\text { reported }\end{array}$ & $\begin{array}{l}\text { Number of } \\
\text { subjects }\end{array}$ & $\begin{array}{l}\text { Age } \\
\text { (years) }\end{array}$ & $\begin{array}{l}\text { Baseline } \\
\text { HbA1c (\%) }\end{array}$ & $\mathrm{BMI}$ & $\begin{array}{l}\text { Diabetes } \\
\text { duration (years) }\end{array}$ & $\begin{array}{l}\text { Prior CVD/ } \\
\text { HF (\%) }\end{array}$ & $\begin{array}{l}\text { Follow up } \\
\text { (median, years) }\end{array}$ & $\begin{array}{l}\text { Primary } \\
\text { endpoints }\end{array}$ \\
\hline EXAMINE & $\begin{array}{l}\text { Alogliptin } \\
\text { (DPP-4) }\end{array}$ & $2009 / 13$ & 5380 & 61.0 & 8.0 & 28.7 & 7.1 & $100 / 28$ & 1.5 & 3 MACE \\
\hline CARMELINA & $\begin{array}{l}\text { Linagliptin } \\
\text { (DPP-4) }\end{array}$ & $2013 / 18$ & 6979 & 66.1 & 8.0 & 31.4 & 15.0 & $58 / 27$ & 2.2 & 3 MACE \\
\hline SAVOR-TIMI & $\begin{array}{l}\text { Saxagliptin } \\
\text { (DPP-4) }\end{array}$ & 2010/13 & 16,492 & 65.1 & 8.0 & 31.1 & 10.3 & $78 / 13$ & 2.1 & 3 MACE \\
\hline TECOS & $\begin{array}{l}\text { Sitagliptin } \\
\text { (DPP-4) }\end{array}$ & $2008 / 15$ & 14,671 & 65.4 & 7.2 & 30.2 & 11.6 & $74 / 18$ & 3.0 & 4 MACE \\
\hline HARMONY & $\begin{array}{l}\text { Albiglutide } \\
\text { (GLP-1) }\end{array}$ & 2015/18 & 9463 & 64.1 & 8.7 & 32.3 & 14.1 & $70 / 20$ & 1.6 & 3 MACE \\
\hline EXSCEL & $\begin{array}{l}\text { Exenatide } \\
\text { (GLP-1) }\end{array}$ & 2010/17 & 14,752 & 62.0 & 8.0 & 31.8 & 12.0 & $73 / 16$ & 3.2 & 3 MACE \\
\hline LEADER & $\begin{array}{l}\text { Liraglutide } \\
\text { (GLP-1) }\end{array}$ & 2010/16 & 9340 & 64.3 & 8.7 & 32.5 & 12.8 & $81 / 18$ & 3.8 & 3 MACE \\
\hline ELIXA & $\begin{array}{l}\text { Lixisenatide } \\
\text { (GLP-1) }\end{array}$ & 2010/15 & 6068 & 60.3 & 7.7 & 30.2 & 9.3 & $100 / 22$ & 2.1 & 4 MACE \\
\hline SUSTAIN-6 & $\begin{array}{l}\text { Semaglutide } \\
\text { (GLP-1) }\end{array}$ & $2013 / 16$ & 3297 & 64.6 & 8.7 & 32.8 & 13.9 & $60 / 24$ & 2.1 & 3 MACE \\
\hline CANVAS & $\begin{array}{l}\text { Canagliflozin } \\
\text { (SGLT2) }\end{array}$ & 2009/17 & 10,142 & 63.3 & 8.2 & 32.0 & 13.5 & $66 / 14$ & 3.6 & 3 MACE \\
\hline $\begin{array}{l}\text { DECLARE- } \\
\text { TIMI }\end{array}$ & $\begin{array}{l}\text { Dapagliflozin } \\
\text { (SGLT2) }\end{array}$ & 2013/18 & 17,160 & 63.9 & 8.3 & 32.1 & 11.0 & $41 / 10$ & 4.2 & 3 MACE \\
\hline $\begin{array}{l}\text { EMPA-REG } \\
\text { OUTCOME }\end{array}$ & $\begin{array}{l}\text { Empagliflozin } \\
\text { (SGLT2) }\end{array}$ & 2010/15 & 7028 & 63.1 & 8.1 & 30.7 & $57 \%>10$ years & $99 / 10$ & 3.1 & 3 MACE \\
\hline
\end{tabular}

BMI Body mass index, CVD Cardiovascular disease, DPP-4 Dipeptidyl peptidase-4 inhibitor, GLP-1 Glucagon-like peptide 1 agonist, HF Heart failure, 3 MACE Threecomponent major adverse cardiovascular events (cardiovascular death, nonfatal myocardial infarction, and nonfatal stroke), 4 MACE Four-component major adverse cardiovascular events (cardiovascular death, nonfatal myocardial infarction, nonfatal stroke, and hospitalization for unstable angina), SGLT2 Sodium glucose cotransporter 2 inhibitor

the use of open-label hypoglycemic agents was encouraged as required to help all patients reach appropriate $\mathrm{HbA1c}$ targets according to local guidelines. Other CV risk factors (e.g., blood pressure, lipids) were also managed on the basis of local guidelines. The sources of data for hypoglycemic agents at baseline and during each trial were provided as supplementary appendices in the original reports. The number of patients who received additional hypoglycemic agents during the trial was significantly greater in the placebo group than in the treatment group in 10 of the CVOTs, i.e., CARMELINA [21], SAVORTIMI [22], TECOS [23], HARMONY [24], EXSCEL [25], LEADER [26], SUSTAIN-6 [28], CANVAS [29], DECLARE-TIMI [30], and EMPA-REG OUTCOME [31, 32]. In the other two trials, namely the EXAMINE [19, 20] and ELIXA trials [27], hypoglycemic agents introduced post-baseline were not reported either in the article or its supplementary appendix. Regardless of whether a greater number of patients in the placebo group received additional hypoglycemic agents, HbA1c concentrations were substantially higher (from 0.27 to 1.00 ) in the placebo group than in the treatment group in all CVOTs throughout the observational period (second column from the left in Table 2). This difference in glycemic control was statistically significant in all CVOTs. In several trials, unfavorable $\mathrm{CV}$ events were more frequent in the treatment group (despite better glycemic control) than in the placebo group. In the EXAMINE trial [20], among participants without a history of heart failure at baseline, the risk of hospital admission for heart failure was significantly higher in the alogliptin group than in the placebo group. The SAVOR-TIMI trial [22] illustrated that more patients were hospitalized for heart failure in the saxagliptin group than in the placebo group. The CANVAS [29] trial found that canagliflozin doubled the risk for lower-limb amputation.

\section{Macrovascular outcomes (Table 2)}

In five trials (HARMONY [24], LEADER [26], SUST AIN-6 [28], CANVAS [29], and EMPA-REG OUTCOME $[31,32])$, the primary outcome was achieved in significantly fewer patients in the treatment group than in the placebo group, whereas no significant difference in the primary outcome was observed between the treatment and placebo groups in the other seven trials. Among the CV events, the event for which a significant reduction in risk was observed in the treatment group differed depending upon the trials as follows: $\mathrm{CV}$ death 
Table $2 \mathrm{HbA} 1 \mathrm{c}$ imbalance, additional hypoglycemic agents, and outcomes in the cardiovascular outcome trials

\begin{tabular}{|c|c|c|c|c|c|c|c|c|c|}
\hline Trial & $\begin{array}{l}\mathrm{HbA1c} \\
\text { imbalance }^{\mathrm{a}}\end{array}$ & $\begin{array}{l}\text { Additional } \\
\text { hypoglycemic } \\
\text { agents }\end{array}$ & $\begin{array}{l}\text { Primary } \\
\text { endpoint }\end{array}$ & $\begin{array}{l}\text { Cardiovascular } \\
\text { death }\end{array}$ & $\begin{array}{l}\text { Nonfatal } \\
\text { Ml }\end{array}$ & $\begin{array}{l}\text { Nonfatal } \\
\text { Stroke }\end{array}$ & $\begin{array}{l}\text { Heart } \\
\text { failure }\end{array}$ & $\begin{array}{l}\text { Death from } \\
\text { any cause }\end{array}$ & $\begin{array}{l}\text { Increased adverse } \\
\text { events }\end{array}$ \\
\hline EXAMINE & $\begin{array}{l}0.36 \\
\text { (mean) }\end{array}$ & NA & $\begin{array}{l}0.96(0.8- \\
1.16)\end{array}$ & $\begin{array}{l}0.79(0.60- \\
1.04)\end{array}$ & $\begin{array}{l}1.08 \\
(0.88- \\
1.33)\end{array}$ & $\begin{array}{l}0.91 \\
(0.55- \\
1.50)\end{array}$ & $\begin{array}{l}1.76^{\complement} \\
(1.07- \\
2.90)\end{array}$ & $\begin{array}{l}0.88(0.71- \\
1.13)\end{array}$ & Heart failure \\
\hline CARMELINA & $\begin{array}{l}0.36 \\
\text { (mean) }\end{array}$ & More in $P$ group & $\begin{array}{l}1.02(0.89- \\
1.17)\end{array}$ & $\begin{array}{l}0.96(0.81- \\
1.14)\end{array}$ & $\begin{array}{l}1.15 \\
(0.91- \\
1.45)\end{array}$ & $\begin{array}{l}0.88 \\
(0.63- \\
1.23)\end{array}$ & $\begin{array}{l}0.90(0.74- \\
1.08)\end{array}$ & $\begin{array}{l}0.98(0.84- \\
1.09)\end{array}$ & \\
\hline SAVOR-TIMI & $0.3\left(52^{d}\right)$ & More in $\mathrm{P}$ group & $\begin{array}{l}1.00(0.98- \\
1.12)\end{array}$ & $\begin{array}{l}1.03(0.87- \\
1.22)\end{array}$ & $\begin{array}{l}0.95 \\
(0.80- \\
1.12)\end{array}$ & $\begin{array}{l}1.11 \\
(0.88- \\
1.39)\end{array}$ & $\begin{array}{l}1.27 \\
(1.07- \\
1.51)\end{array}$ & $\begin{array}{l}1.11(0.96- \\
1.27)\end{array}$ & Heart failure \\
\hline TECOS & $\begin{array}{l}0.29 \\
\text { (mean) }\end{array}$ & More in $P$ group & $\begin{array}{l}0.98(0.89- \\
1.08)\end{array}$ & $\begin{array}{l}1.03(0.89- \\
1.19)\end{array}$ & $\begin{array}{l}0.96 \\
(0.81- \\
1.13)^{\mathrm{e}}\end{array}$ & $\begin{array}{l}0.93 \\
(0.75- \\
1.16)^{f}\end{array}$ & $\begin{array}{l}1.00(0.83- \\
1.20)\end{array}$ & $\begin{array}{l}1.01(0.90- \\
1.14)\end{array}$ & \\
\hline HARMONY & $0.63\left(8^{d}\right)$ & More in $\mathrm{P}$ group & $\begin{array}{l}0.78(0.68- \\
0.90)\end{array}$ & $\begin{array}{l}0.93(0.73- \\
1.19)\end{array}$ & $\begin{array}{l}0.75 \\
(0.61- \\
0.90)^{e}\end{array}$ & $\begin{array}{l}0.86 \\
(0.66- \\
1.14)^{f}\end{array}$ & $\begin{array}{l}0.85(0.70- \\
1.04)\end{array}$ & $\begin{array}{l}0.95(0.79- \\
1.16)\end{array}$ & \\
\hline EXSCEL & $\begin{array}{l}0.53 \\
\text { (mean) }\end{array}$ & More in $P$ group & $\begin{array}{l}0.91(0.83- \\
1.00)\end{array}$ & $\begin{array}{l}0.88(0.73- \\
1.05)\end{array}$ & $\begin{array}{l}0.95 \\
(0.84- \\
1.09)\end{array}$ & $\begin{array}{l}0.86 \\
(0.70- \\
1.07)\end{array}$ & $\begin{array}{l}0.94(0.78- \\
1.13)\end{array}$ & $\begin{array}{l}0.86(0.77- \\
0.97)\end{array}$ & \\
\hline LEADER & $0.4\left(36^{d}\right)$ & More in $\mathrm{P}$ group & $\begin{array}{l}0.87(0.78- \\
0.97)\end{array}$ & $0.78(0.66-0.93)$ & $\begin{array}{l}0.88 \\
(0.75- \\
1.03)\end{array}$ & $\begin{array}{l}0.89 \\
(0.72- \\
1.11)\end{array}$ & $\begin{array}{l}0.87(0.73- \\
1.05)\end{array}$ & $\begin{array}{l}0.85(0.74- \\
0.97)\end{array}$ & \\
\hline ELIXA & $\begin{array}{l}0.27 \\
\text { (mean) }\end{array}$ & NA & $\begin{array}{l}1.02(0.89- \\
1.17)\end{array}$ & $\begin{array}{l}0.98(0.78- \\
1.22)\end{array}$ & $\begin{array}{l}1.03 \\
(0.87- \\
1.22)\end{array}$ & $\begin{array}{l}1.12 \\
(0.79- \\
1.58)\end{array}$ & $\begin{array}{l}0.96(0.75- \\
1.23)\end{array}$ & $\begin{array}{l}0.94(0.78- \\
1.13)\end{array}$ & \\
\hline SUSTAIN-6 & $1.00\left(104^{d}\right)$ & More in $\mathrm{P}$ group & $\begin{array}{l}0.74(0.58- \\
0.95)\end{array}$ & $\begin{array}{l}0.98(0.65- \\
1.48)\end{array}$ & $\begin{array}{l}0.74 \\
(0.51- \\
1.08)\end{array}$ & $\begin{array}{l}0.61 \\
(0.38- \\
0.99)\end{array}$ & $\begin{array}{l}1.11(0.77- \\
1.61)\end{array}$ & $\begin{array}{l}1.05(0.74- \\
1.50)\end{array}$ & \\
\hline CANVAS & $\begin{array}{l}0.58 \\
\text { (mean) }\end{array}$ & More in $P$ group & $\begin{array}{l}0.86(0.75- \\
0.97)\end{array}$ & $\begin{array}{l}0.87(0.72- \\
1.06)\end{array}$ & $\begin{array}{l}0.85 \\
(0.69- \\
1.05)\end{array}$ & $\begin{array}{l}0.90 \\
(0.71- \\
1.15)\end{array}$ & $\begin{array}{l}0.67(0.52- \\
0.87)\end{array}$ & $\begin{array}{l}0.87(0.74- \\
1.01)\end{array}$ & Amputation \\
\hline $\begin{array}{l}\text { DECLARE- } \\
\text { TIMI }\end{array}$ & $\begin{array}{l}0.42 \\
\text { (mean) }\end{array}$ & More in $P$ group & $\begin{array}{l}0.93(0.84- \\
1.03)\end{array}$ & $\begin{array}{l}0.98(0.82- \\
1.17)\end{array}$ & $\begin{array}{l}0.89 \\
(0.77- \\
1.01)\end{array}$ & $\begin{array}{l}1.01 \\
(0.84- \\
1.21)\end{array}$ & $\begin{array}{l}0.73(0.61- \\
0.88)\end{array}$ & $\begin{array}{l}0.93(0.82- \\
1.04)\end{array}$ & $\begin{array}{l}\text { Ketoacidosis } \\
\text { Genital infection }\end{array}$ \\
\hline $\begin{array}{l}\text { EMPA-REG } \\
\text { OUTCOME }\end{array}$ & $0.47\left(94^{d}\right)$ & More in $\mathrm{P}$ group & $\begin{array}{l}0.86(0.74- \\
0.99)\end{array}$ & $0.62(0.49-0.77)$ & $\begin{array}{l}0.87 \\
(0.70- \\
1.09)\end{array}$ & $\begin{array}{l}1.24 \\
(0.92- \\
1.67)\end{array}$ & $\begin{array}{l}0.65(0.50- \\
0.85)\end{array}$ & $\begin{array}{l}0.68(0.57- \\
0.82)\end{array}$ & \\
\hline
\end{tabular}

${ }^{\mathrm{a}} \mathrm{HbA1c}$ concentrations were significantly higher in the placebo group than in the treatment group. ${ }^{\mathrm{b}}$ Adverse events that had a significant increase in frequency in the treatment group. ' In patients without a history of heart failure at baseline. ${ }^{\mathrm{d}}$ Week at which the data were obtained. ${ }^{\mathrm{e}}$ Fatal myocardial infarction included. ${ }^{\mathrm{f}}$ Fatal stroke included. Data are presented as the hazard ratio ( $95 \%$ confidence interval). Bold type represents a significant increase of the event in the treatment group compared with that in the placebo group. Italic type represents a significant reduction. MI Myocardial infarction, NA Data not available, $P$ Placebo

was reduced in the LEADER [26] and EMPA-REG OUTCOME [31, 32] trials; hospital admission for heart failure was reduced in the CANVAS [29], DECLARE-TIMI [30], and EMPA-REG OUTCOME [31, 32] trials; myocardial infarction was reduced only in the HARMONY [24] trial; nonfatal stroke was reduced only in the SUST AIN-6 [28] trial; and heart failure was reduced in the CANVAS [29], DECLARE-TIMI [30], and EMPA-REG OUTCOME $[31,32]$ trials.

\section{Microvascular outcomes}

Although nephropathy was evaluated in all CVOTs, the outcome measure varied and the effects were inconsistent. The estimated glomerular filtration rate was comparable between the treatment and placebo groups in the EXAMINE $[19,20]$ and HARMONY [24] trials, whereas it was lower in the sitagliptin group in the TECOS trial [23]. The urinary albumin-to-creatinine ratio (UACR) showed significantly less worsening in the linagliptin and saxagliptin groups in the CARMELINA [21] and SAVOR-TIMI [22] trials, respectively. In the ELIXA [27] trial, the pre-specified analysis of the percentage change in the UACR from baseline to 108 weeks was significantly different in favor of lixisenatide over placebo $(24 \%$ vs. $34 \% ; P=0.004)$, but upon post hoc analysis with adjustment for HbA1c, this difference was attenuated $(P=0.07)$ [27]. In the EXSCEL [25] trial, no significant difference was observed in the incidence of micro- and macroalbuminuria between the 
exenatide and placebo groups. In the LEADER [26], SUST AIN-6 [28], CANVAS [29], DECLARE-TIMI [30], and EMPA-REG OUTCOME $[31,32]$ trials, the renal composite endpoint was significantly reduced in in favor of the treatment group. Retinopathy, which was included in as an outcome measure in five of the CVOTs, had a comparable frequency between the groups in EXSCEL [25], whereas it was more frequent in the treatment group in the TECOS [23], LEADER [26], and SUSTAIN-6 [28] trials. In the CARMELINA [21] trial, retinopathy was less common in the linagliptin group. Neuropathy, which was evaluated only in the EXSCEL [25] trial, did not have a significantly different incidence between the groups.

\section{Discussion}

These CVOTs generated interpretative challenges. The use of open-label hypoglycemic agents was encouraged to minimize the confounding effects of differences in glycemic control. Despite the cautious designs, HbA1c concentrations were substantially higher in the placebo group than in the treatment group in all of the CVOTs. This imbalance, which can potentially obscure the risk of the test drug, means that subjects in the placebo group had inferior glycemic control than those in the treatment group. Of note, the investigators of the EXSCEL [25] trial stated that the significant reduction in the risk of death from any cause in the exenatide group might have been influenced by the inferior glycemic control in the placebo group. The non-glucose effects that are often associated with newer hypoglycemic agents [12], e.g., changes in body weight, blood pressure, and LDL-cholesterol, could also introduce imbalances. These confounders challenge the interpretation of outcomes for the hypoglycemic agents tested in the CVOTs. The greater use of additional hypoglycemic agents in the placebo group than the treatment group in 10 of the CVOTs represented another potential confounder. The imbalance of HbA1c concentrations between 0.27 and $1.00 \%$ should not be dismissed because it is comparable to that in the UKPDS 34 study [3], in which the median HbA1c concentrations during 10 years of follow-up were $7.4 \%$ in the metformin group and $8.0 \%$ in the conventional treatment group. Adjustment for predictive baseline characteristics, even when largely balanced, may lead to clearly different estimates of the effect of treatment on CV outcomes [33]. Re-analysis of the data in the CVOTs with adjustment for HbA1c would determine whether the results were biased by the difference in glycemic control between the treatment and placebo groups and reveal the potential effects of the test drugs independent of glycemic control [34, 35].

The primary endpoint that was used in all of the CVOTs complicated the evaluation of efficacy. The use of composite endpoints [36] can potentially distort trials of a new antidiabetic therapies for treating T2D. In particular, whereas the CVOTs aimed to establish safety, composite endpoints were originally designed to determine overall efficacy. We cannot determine whether any of the observed difference between the treatment and placebo arms are independent of glycemic control. Although the imbalance was present in all of the CVOTs, none provided data corrected for the imbalance in HbA1c. Only the post hoc analysis of the EXAMINE trial [37] revealed the absence of relationships of baseline $\mathrm{HbAlc}$ or HbA1c after 1 month of treatment with the risk of MACE. To draw a more robust conclusion, further in-depth analyses considering the aforementioned biases, including the imbalance in HbA1c between the treatment and placebo groups, are required.

Glycemic control is expected to reduce the risk of heart failure [38], which is generally regarded as a CV event. However, only three of the CVOTs (the CANVAS [29], DECLARE-TIMI [30], and EMPA-REG OUTCOME [31, 32] trials) reported reductions in heart failure risk despite the substantially lower HbAlc concentrations in the treatment group than in the placebo group in all of the CVOTs. Indeed, in the EXAMINE [19, 20] and SAVOR-TIMI [22] trials, the risk of heart failure was higher in the treatment group than in the placebo group. In response to these results, the FDA added a heart failure warning to the labels of alogliptin and saxagliptin [39]. The agency subsequently added the same warning to the labels of linagliptin [40] and sitagliptin [41] despite no finding of an increase in heart failure risk in either the CARMELINA [21] or TECOS [23] trial, and the association between DPP-4 inhibitors and heart failure as a class effect remains uncertain [42].

Whereas GLP-1 agonists reduced the risk of myocardial ischemia and heart failure in the early studies [43, 44], no reduction in heart failure risk was observed in the HARMONY [24], EXSCEL [25], LEADER [26], ELIXA [27], or SUSTAIN-6 [28] trials despite the substantially lower HbA1c concentrations in the treatment group than in the placebo group. Liraglutide was studied in patients with T2D and heart failure in two smaller trials in addition to the five CVOTs of GLP-1 agonists reviewed in this study. In the LIVE trial [45], whereas 24 weeks of liraglutide treatment had no effect on left ventricular systolic function in 241 patients with T2D and chronic heart failure, a higher rate of adverse cardiac events was observed (12 in the liraglutide group versus three in the placebo group). The FIGHT trial [46], which enrolled 178 patients with T2D and 122 without T2D to test whether liraglutide improves clinical stability following hospitalization for acute heart failure, failed to demonstrate any benefit of liraglutide. Moreover, subgroup analysis of patients with T2D revealed a non-significant increase in the number of deaths or re-hospitalizations for heart failure $(\mathrm{HR}=1.54,95 \% \mathrm{CI}=0.97-2.46 ; P=0.07)$ in 
the liraglutide group compared with the placebo group. On the basis of the fact that only $18 \%$ of the LEADER [26] trial population was reported to have heart failure at baseline, the results of the LIVE and FIGHT trials raise safety concerns regarding the use of liraglutide in patients with T2D and heart failure.

In contrast to DPP-4 inhibitors and GLP-1 agonists, the SGLT2 inhibitors canagliflozin, dapagliflozin, and empagliflozin reduced the risk of heart failure in the CANVAS [29], DECLARE-TIMI [30], and EMPA-REG OUTCOME [31, 32] trials, respectively. However, we should exercise caution in interpreting these data because the inferior glycemic control in the placebo group might have affected the outcome in favor of the treatment group. These SGLT2 inhibitors were reported to be associated with a 2 -fold higher risk for amputation in a register-based cohort study [47]. This may be a class effect of SGLT2 inhibitors rather than an effect specific to canagliflozin (which has a boxed warning about amputation on its label) because the proportions of patients who used dapagliflozin, empagliflozin, and canagliflozin in the study were 61,38 , and $1 \%$, respectively. Regarding microvascular outcomes, the attenuation of the favorable UACR outcome for lixisenatide after adjustment for HbA1c [27] indicates a need for comprehensive re-analysis of the data in the CVOTs. The increase in the risk of retinopathy observed in the TECOS [23], LEADER [26], and SUSTAIN-6 [28] trials represents another concern.

Our study found that lower HbA1c concentrations in the treatment group throughout the trial do not necessarily improve CV outcomes in patients with T2D. HbA1c remains the best marker for monitoring drug effects on T2D, and the strengths and limitations of HbA1c first need to be determined. Biological variation in hemoglobin glycation [48] is one of the new research directions to validate $\mathrm{HbA1c}$ as a surrogate in T2D [49]. Monitoring blood glucose and $\mathrm{HbA1c}$ concentrations closely in randomized controlled trials may therefore be a promising option to assess the biological variation in HbA1c.

Our study has limitations. First, its cross-sectional study design does not permit determinations of cause and effect, making interpretation of the data inferential. We could not identify the cause of the imbalance of glycemic control between the treatment and placebo groups or discriminate any confounding effects. Second, we did not have the data for re-analysis to investigate the effects of the imbalance of glycemic control on the results of the CVOTs, which must be a focus of public attention. These limitations restrict the applicability of our study results to other studies.

\section{Conclusion}

The safety and efficacy of new hypoglycemic agents are of particularly great concern to patients with diabetes.
The imbalance in glycemic control observed in CVOTs evaluating hypoglycemic drugs placed the patients in the placebo groups at potential risk for $\mathrm{CV}$ events. Misinterpretation of data from these trials could lead to incorrect evaluation of both the efficacy and safety of the drug and eventually harm patients. Our study will help the FDA and other regulatory bodies to critically review CVOTs in this area from a regulatory perspective because additional CVOTs to address the FDA 2008 guidance are ongoing. The FDA should require re-analysis with adjustment for $\mathrm{HbA1c}$ to rule out potential biases against the safety and efficacy of the tested drug, which are of crucial concern. The re-analysis would determine whether the results of the CVOTs were biased by the difference in glycemic control between the treatment and placebo groups. Further review of these CVOTs regarding the imbalance of $\mathrm{HbA1c}$ will lead to precise interpretation of the data and correct evaluation of the tested hypoglycemic agents in future trials.

\section{Abbreviations}

CANVAS: Canagliflozin Cardiovascular Assessment Study;

CARMELINA: Cardiovascular and Renal Microvascular Outcome Study With Linagliptin; Cl: Confidence interval; CV: Cardiovascular; CVOTs: Cardiovascular outcome trials; DECLARE-TIMI: Dapagliflozin Effect on Cardiovascular EventsThrombolysis in Myocardial Infarction; DPP-4: Dipeptidyl peptidase-4;

ELIXA: Evaluation of Lixisenatide in Acute Coronary Syndrome; EMPA-REG

OUTCOME: Empagliflozin, Cardiovascular Outcomes, and Mortality in Type 2

Diabetes; EXAMINE: Examination of Cardiovascular Outcomes with Alogliptin versus Standard of Care; EXSCEL: Exenatide Study of Cardiovascular Event Lowering; FDA: United States Food and Drug Administration;

FIGHT: Functional Impact of GLP-1 for Heart Failure Treatment; GLP-

1: glucagon-like peptide-1; HARMONY: Albiglutide and cardiovascular outcomes in patients with type 2 diabetes and cardiovascular disease; HbA1c: Glycated hemoglobin; HR: hazard ratio; LEADER: Liraglutide Effect and Action in Diabetes Evaluation of Cardiovascular Outcome Results; LIVE: Effect of Liraglutide on Left Ventricular Function in Chronic Heart Failure Patients With and Without Type 2 Diabetes; MACE: major adverse cardiovascular events; SAVOR-TIMI: Saxagliptin Assessment of Vascular Outcomes Recorded in Patients with Diabetes Mellitus-Thrombolysis in Myocardial Infarction; SGLT2: sodium glucose cotransporter 2; SUSTAIN 6: Semaglutide and Cardiovascular Outcomes in Patients with Type 2 Diabetes; T2D: Type 2 diabetes mellitus; TECOS: Trial Evaluating Cardiovascular Outcomes with Sitagliptin; UACR: Urinary albumin to creatinine ratio; UKPDS: United Kingdom Prospective Diabetes Study

\section{Acknowledgements}

We thank Edanz Group (www.edanzediting.com/ac) for editing a draft of this manuscript.

\section{Authors' contributions \\ RS participated in the development of the study design and methods, gathered data on regulation, and provided a critical review of the manuscript. Ml conceived the original study idea, gathered data on cardiovascular outcome trials, conducted statistical analyses, and produced the initial draft of the manuscript. All authors read and approved the final manuscript.}

\section{Funding}

This study was supported by a Grant-in-Aid for Scientific Research (C) (16 K08882, RS; 17 K08919, MI) from the Japan Society for the Promotion of Science. The Japan Society for the Promotion of Science had no role in the design and conduct of the study; collection, management, analysis, and interpretation of the data; preparation, review, or approval of the manuscript; or the decision to submit the manuscript for publication. 


\section{Availability of data and materials}

All data generated or analyzed during this study are included in this published article.

\section{Ethics approval and consent to participate}

Not applicable.

\section{Consent for publication}

Not applicable.

\section{Competing interests}

The authors declare that they have no competing interests.

\section{Author details}

'Department of Clinical Pharmacology, Tokai University School of Medicine, Isehara, Kanagawa 259-1193, Japan. ${ }^{2}$ Department of Medical Informatics, Kagawa University Hospital, Miki-cho, Kagawa 761-0793, Japan.

Received: 25 January 2019 Accepted: 23 August 2019 Published online: 18 November 2019

\section{References}

1. Nathan DM, Kuenen J, Borg R, Zheng H, Schoenfeld D, Heine RJ. Translating the A1C assay into estimated average glucose values. Diabetes Care. 2008; 31:1473-8.

2. Ray KK, Seshasai SR, Wijesuriya S, et al. Effect of intensive control of glucose on cardiovascular outcomes and death in patients with diabetes mellitus: a meta-analysis of randomised controlled trials. Lancet. 2009:373:1765-72.

3. UK Prospective Diabetes Study Group. Effect of intensive blood-glucose control with metformin on complications in overweight patients with type 2 diabetes (UKPDS 34). Lancet. 1998;352:854-65.

4. USFDA. FDA Background Document. Endocrinologic and Metabolic Drugs Advisory Committee Meeting October 24-25, 2018. https://www.fda.gov/ downloads/AdvisoryCommittees/CommitteesMeetingMaterials/Drugs/ EndocrinologicandMetabolicDrugsAdvisoryCommittee/UCM623913.pdf. Accessed 27 July 2019.

5. Nissen SE, Wolski K, Topol EJ. Effect of muraglitazar on death and major adverse cardiovascular events in patients with type 2 diabetes mellitus. JAMA. 2005;294:2581-6.

6. Finkelstein JB. Drug safety system needs overhaul, experts say. J Natl Cancer Inst. 2006;98:379-81.

7. Nissen SE, Wolski K. Effect of rosiglitazone on the risk of myocardial infarction and death from cardiovascular causes. N Engl J Med. 2007;356:2457-71.

8. Home PD, Pocock SJ, Beck-Nielsen H, et al. Rosiglitazone evaluated for cardiovascular outcomes in oral agent combination therapy for type 2 diabetes (RECORD): a multicentre, randomised, open-label trial. Lancet. 2009; 373:2125-35.

9. US FDA. Guidance for Industry. Diabetes Mellitus - Evaluating Cardiovascular Risk in New Antidiabetic Therapies to Treat Type 2 Diabetes. https://www.fda.gov/media/71297/download. Accessed 27 July 2019.

10. Cefalu WT, Kaul S, Gerstein HC, et al. Cardiovascular outcomes trials in type 2 diabetes: where do we go from Here? Reflections from a diabetes care Editors' expert forum. Diabetes Care. 2018:41:14-31.

11. Schnell O, Standl E, Catrinoiu D, et al. Report from the 3rd cardiovascular outcome trial (CVOT) summit of the Diabetes \& Cardiovascular Disease (D\&CVD) EASD study group. Cardiovasc Diabetol. 2018;17:30.

12. Holman RR, Sourij H, Califf RM. Cardiovascular outcome trials of glucoselowering drugs or strategies in type 2 diabetes. Lancet. 2014;383:2008-17.

13. Venker BT. Hemoglobin A1c as a surrogate for clinical outcomes in diabetes studies. JAMA. 2017;318:200.

14. Rodriguez-Gutierrez R, Montori VM. Glycemic control for patients with type 2 diabetes mellitus: our evolving faith in the face of evidence. Circ Cardiovasc Qual Outcomes. 2016;9:504-12.

15. Lipska K, Krumholz HM. Hemoglobin A1C as a surrogate for clinical outcomes in diabetes studies-reply. JAMA. 2017;318:200-1.

16. CenterWatch. FDA Approved Drugs. https://www.centerwatch.com/druginformation/fda-approvals/. Accessed 27 July 2019.

17. United States National Libracy of Medicine. ClinicalTrials.gov. https:// clinicaltrials.gov/. Accessed 27 July 2019.

18. US Department of Health and Human Services. Clinical Trials Registration and Results Information Submission. https://www.federalregister.gov/ documents/2016/09/21/2016-22129/clinical-trials-registration-and-resultsinformation-submission. Accessed 27 July 2019

19. White WB, Cannon CP, Heller SR, et al. Alogliptin after acute coronary syndrome in patients with type 2 diabetes. N Engl J Med. 2013;369:1327-35.

20. Zannad F, Cannon CP, Cushman WC, et al. Heart failure and mortality outcomes in patients with type 2 diabetes taking alogliptin versus placebo in EXAMINE: a multicentre, randomised, double-blind trial. Lancet. 2015;385:2067-76.

21. Rosenstock J, Perkovic V, Johansen OE, et al. Effect of Linagliptin vs placebo on major cardiovascular events in adults with type 2 diabetes and high cardiovascular and renal risk. The CARMELINA randomized clinical trial. JAMA. 2019;321:69-79.

22. Scirica BM, Bhatt DL, Braunwald E, et al. Saxagliptin and cardiovascular outcomes in patients with type 2 diabetes mellitus. N Engl J Med. 2013:369:1317-26.

23. Green JB, Bethel MA, Armstrong PW, et al. Effect of Sitagliptin on cardiovascular outcomes in type 2 diabetes. N Engl J Med. 2015;373:232-42.

24. Hernandez AF, Green JB, Janmohamed S, et al. Albiglutide and cardiovascular outcomes in patients with type 2 diabetes and cardiovascular disease (Harmony Outcomes): a double-blind, randomised placebo-controlled trial. Lancet. 2018:392:1519-29.

25. Holman RR, Bethel MA, Mentz RJ, et al. Effects of once-weekly Exenatide on cardiovascular outcomes in type 2 diabetes. N Engl J Med. 2017:377:1228-39.

26. Marso SP, Daniels GH, Brown-Frandsen K, et al. Liraglutide and cardiovascular outcomes in type 2 diabetes. N Engl J Med. 2016:375:311-22.

27. Pfeffer MA, Claggett B, Diaz R, et al. Lixisenatide in patients with type 2 diabetes and acute coronary syndrome. N Engl J Med. 2015;373:2247-57.

28. Marso SP, Bain SC, Consoli A, et al. Semaglutide and cardiovascular outcomes in patients with type 2 diabetes. N Engl J Med. 2016;375:1834-44.

29. Neal B, Perkovic V, Mahaffey KW, et al. Canagliflozin and cardiovascular and renal events in type 2 diabetes. N Engl J Med. 2017;377:644-57.

30. Wiviott SD, Raz I, Bonaca MP, et al. Dapagliflozin and Cardiovascular Outcomes in Type 2 Diabetes. N Engl J Med. 2019;380:347-57.

31. Zinman B, Wanner C, Lachin JM, et al. Empagliflozin, cardiovascular outcomes, and mortality in type 2 diabetes. N Engl J Med. 2015;373:2117-28.

32. Wanner C, Inzucchi SE, Lachin JM, et al. Empagliflozin and progression of kidney disease in type 2 diabetes. N Engl J Med. 2016;375:323-34

33. Steyerberg EW, Bossuyt PM, Lee KL. Clinical trials in acute myocardial infarction: should we adjust for baseline characteristics? Am Heart J. 2000;139:745-51.

34. Rowlands J, Heng J, Newsholme P, Carlessi R. Pleiotropic effects of GLP-1 and analogs on cell signaling, metabolism, and function. Front Endocrinol (Lausanne). 2018:9:672.

35. Vallon V, Thomson SC. Targeting renal glucose reabsorption to treat hyperglycaemia: the pleiotropic effects of SGLT2 inhibition. Diabetologia. 2017;60:215-25.

36. Ferreira-Gonzalez I, Busse JW, Heels-Ansdell D, et al. Problems with use of composite end points in cardiovascular trials: systematic review of randomised controlled trials. BMJ. 2007;334:786.

37. Heller SR, Bergenstal RM, White WB, et al. Relationship of glycated haemoglobin and reported hypoglycaemia to cardiovascular outcomes in patients with type 2 diabetes and recent acute coronary syndrome events: the EXAMINE trial. Diabetes Obes Metab. 2017;19:664-71.

38. Aneja A, Tang WH, Bansilal S, Garcia MJ, Farkouh ME. Diabetic cardiomyopathy: insights into pathogenesis, diagnostic challenges, and therapeutic options. Am J Med. 2008;121:748-57.

39. US FDA. FDA Drug Safety Communication: FDA adds warnings about heart failure risk to labels of type 2 diabetes medicines containing saxagliptin and alogliptin. https://www.fda.gov/Drugs/DrugSafety/ucm486096.htm. Accessed 27 July 2019.

40. US FDA. Supplement approval: NDA 201280/S-016, NDA 201281/S-019, NDA 208026/S-005, NDA 206073/S-013. https:/www.accessdata.fda.gov/ drugsatfda_docs/appletter/2017/201280Orig1s016,201281 Orig1s019,208026 Orig1 1005,2060730rig15013ltr.pdf. Accessed 27 July 2019.

41. US FDA. Supplement approval: NDA 021995/S-040, NDA 022044/S-042, NDA 202270/S-017. https://www.accessdata.fda.gov/drugsatfda_docs/appletter/2 017/021995Orig1s040,022044Orig1 s042,2022700rig1s017/tr.pdf. Accessed 27 July 2019.

42. Verma S, Goldenberg RM, Bhatt DL, et al. Dipeptidyl peptidase-4 inhibitors and the risk of heart failure: a systematic review and meta-analysis. CMAJ Open. 2017:5:E152-77.

43. Nikolaidis LA, Mankad S, Sokos GG, et al. Effects of glucagon-like peptide-1 in patients with acute myocardial infarction and left ventricular dysfunction after successful reperfusion. Circulation. 2004;109:962-5. 
44. Sokos GG, Nikolaidis LA, Mankad S, Elahi D, Shannon RP. Glucagon-like peptide-1 infusion improves left ventricular ejection fraction and functional status in patients with chronic heart failure. J Card Fail. 2006;12:694-9.

45. Jorsal A, Kistorp C, Holmager P, et al. Effect of liraglutide, a glucagon-like peptide-1 analogue, on left ventricular function in stable chronic heart failure patients with and without diabetes (LIVE)-a multicentre, double-blind, randomised, placebo-controlled trial. Eur J Heart Fail. 2017;19:69-77.

46. Margulies KB, Hernandez AF, Redfield MM, et al. Effects of Liraglutide on clinical stability among patients with advanced heart failure and reduced ejection fraction: a randomized clinical trial. JAMA. 2016;316:500-8.

47. Ueda P, Svanstrom H, Melbye M, et al. Sodium glucose cotransporter 2 inhibitors and risk of serious adverse events: nationwide register based cohort study. BMJ. 2018;363:k4365.

48. Cohen RM. A1C: does one size fit all? Diabetes Care. 2007;30:2756-8

49. Malka R, Nathan DM, Higgins JM. Mechanistic modeling of hemoglobin glycation and red blood cell kinetics enables personalized diabetes monitoring. Sci Transl Med. 2016;8:359ra130.

\section{Publisher's Note}

Springer Nature remains neutral with regard to jurisdictional claims in published maps and institutional affiliations.

Ready to submit your research? Choose BMC and benefit from:

- fast, convenient online submission

- thorough peer review by experienced researchers in your field

- rapid publication on acceptance

- support for research data, including large and complex data types

- gold Open Access which fosters wider collaboration and increased citations

- maximum visibility for your research: over $100 \mathrm{M}$ website views per year

At $\mathrm{BMC}$, research is always in progress.

Learn more biomedcentral.com/submissions 